Psicologia \& Sociedade; 16 (1): 135-145; Número Especial 2004

\title{
ATIVIDADE CRIADORA, PRODUÇÃO DE CONHECIMENTOS E FORMAÇÃO DE PESQUISADORES: ALGUMAS REFLEXÓOES
}

Andréa Vieira Zanella Universidade Federal de Santa Catarina

RESUMO: Criatividade é um desses temas que sempre esteve em voga, com maior visibilidade em alguns momentos históricos. Vivemos hoje um desses momentos, pois a demanda da sociedade capitalística, no que se refere ao mercado de trabalho, incide sobre sujeitos criativos, polivalentes, capazes de trabalhar em equipe e com iniciativa. Super sujeitos, na verdade, distantes em muito das condições sociais e educativas em que a maioria da população brasileira se encontra e que poderiam forjá-los. Criar é, portanto, palavra da moda, mas cuja presença e origem remonta a tempos difíceis de precisar, posto que caracteriza o ser humano e todas as suas produções, incluindo-se aí a produção de conhecimentos. Independente de como se objetiva, a atividade criadora funda-se em um olhar que rompe com o imediato e episódico. A constituição desse olhar, por sua vez, decorre de um processo, de intervençôes deliberadas que objetivem romper com a explosão de imagens e mensagens desconexas que caracterizam a realidade atual, destituindo-a de sentidos voltados à crítica e sua transformação. Justifica-se, portanto, a necessidade de reflexôes constantes e pesquisas sobre o tema, posto que a formação de educadores é condição para que novos olhares sejam forjados.

PALAVRAS-CHAVE: criatividade, atividade criadora, constituição do sujeito, formação de pesquisadores, pós-graduação.

\section{CREATOR ACTIVITY, KNOWLEDGE PRODUCTION AND RESEARCHER'S TRAINING: SOME REFLECTIONS}

ABSTRACT: creativity is one of those topics that has always been in vogue, with larger visibility in some historical moments. We live 
Zanella, A. V.

"Atividade criadora, produção de conhecimentos e formação de pesquisadores:

algumas reflexôes"

today one of these moments, for the demand of the capitalistic society, regarding the work market, falls upon creative and pluralistics subjects who are able to work as a team and with initiative. "Super subjects", in fact, distant from the social and educational conditions in which most of Brazilian people are placed and that could forge them. Creating is, therefore, a fashion word, but its presence and origin take us back to difficult times to precise, even because it characterizes the human being and all his productions, including knowledge productions. Independently of its goals, a creator activity is based on a view that breaks up the immediate. The constitution of this view happens from a process, from deliberated interventions which intend to stop the explosion of disconnected images and messages that characterizes the present reality, displacing it from meanings related to criticism and its change. Is is justified, therefore, the necessity of constant reflections and researchs about this topic, even though educators training is a condition for new views to be forged.

KEYWORDS: creativity, creator activity, subject constitution, researcher's training, post-graduation.

Criatividade é um daqueles temas que sempre esteve em voga, com maior visibilidade em alguns momentos históricos. Vivemos hoje um desses momentos, pois a demanda da sociedade capitalística, ${ }^{1}$ no que se refere ao mercado de trabalho, incide sobre sujeitos criativos, polivalentes, capazes de trabalhar em equipe e com iniciativa. Super sujeitos, na verdade, distantes em muito das condiçôes sociais e educativas em que a maioria da população brasileira se encontra e que poderiam forjá-los! ${ }^{2}$

1 A referência à sociedade atual como capitalística é apresentada por Félix Guatarri, "por lhe parecer necessário criar um termo que possa designar não apenas as sociedades qualificadas como capitalistas, mas também setores do 'Terceiro Mundo' ou do capitalismo 'periférico', assim como as economias socialistas dos países do leste, que vivem numa espécie de dependência e contradependência do capitalismo. Tais sociedades, segundo Guattari, em nada se diferenciariam do ponto de vista do modo de produção da subjetividade" (Rolnik 1986 citado por Guattari \& Rolnik, 1986, p.15).

2 Essa afirmação baseia-se em uma concepção de sujeito que é síntese das relações socias, das quais participa como co-autor. Assim, as condiçóes sociais e educativas, 
Essa demanda, porém, deixa em uma situação de impasse a todos que por décadas voltaram seus discursos e práticas para a transformação da realidade injusta e perversa em que se vive, transformação essa em direção a condições dignas de existência para todos bem como para a constituição de sujeitos plenos, capazes de se afirmarem cotidianamente enquanto tal e assim serem reconhecidos. Afinal, não é esse sujeito criativo, flexível e polivalente o que sempre buscamos?

A resposta é sim e não! Sim, na medida em que "Nunca foi tão importante criar, seja para acompanhar a onda da modernidade ou para confrontar-se com ela. Afinal, até os mecanismos de controle e assujeitamento não são mais fixos e padronizados, mas oscilantes, difusos e bastante móveis, exigindo também estratégias de enfrentamento capazes de ensejar ações múltiplas, singulares e versáteis" (JUSTO, 2001, p.63).

Qualquer transformação que se queira consolidar requer, pois, criatividade, e em um mundo onde mudanças são implementadas com uma velocidade estonteante, resultando em mecanismos cada vez mais sofisticados de aprisionamento do ser humano nas amarras da lógica social que imputa a grande parcela da população o lugar da exclusão, a capacidade analítica que permita desvendar essas amarras e produzir estratégias de enfrentamento é imperiosa. Continuamos precisando, portanto, de sujeitos criativos, porque continuamos lutando por condições sociais e políticas que permitam a humanização, a constituição de sujeitos que possam viver com plenitude o que a história da humanidade nos tem possibilitado produzir e possam engendrar ações efetivas no sentido de transformá-la.

Por sua vez, há um demarcador claro em termos de projeto de sociedade e que justifica o não: buscamos sujeitos criativos sim, porém comprometidos com uma lógica outra que não essa lógica excludente imperante que divide grupos sociais, coletividades, naçôes e religiôes, que produz e incentiva intolerâncias de diferentes ordens e se cega a diferentes formas de violência. Ao contrário, buscamos sujeitos comprometidos com outros sujeitos, que acolham as

enfim, as experiências do sujeito que constituem seu modo de vida são determinantes de suas possibilidades de criar e ser reconhecido enquanto tal (sobre a relação realidade e imaginação, ver Vygotski, 1990). 
Zanella, A. V.

"Atividade criadora, produção de conhecimentos e formação de pesquisadores:

algumas reflexôes"

diferenças que nos conotam e possam com elas conviver, que construam relaçôes sociais pautadas em uma ética da e pela vida, enfim, em uma estética da existência. ${ }^{3}$

Esse horizonte, que descola as ações humanas da mera reprodução do existente, do imediato e episódico, pauta-se em uma concepção de ser humano que o considera enquanto objetivação da história da humanidade, mas ao mesmo tempo o projeta para o futuro, para o emergente, para o desconhecido. Como? Esclarece Vygotski (1990, p. 9): "É precisamente a atividade criadora do homem que o faz um ser projetado para o futuro, um ser que contribui a criar e modificar seu presente".

Passado, presente e futuro objetivam-se, portanto, no criar, atividade caracteristicamente humana, presente desde os primórdios da civilização. Esta só é possível na medida em que se estabelece uma relação outra com a realidade que ultrapassa a necessidade da mera sobrevivência, ou seja, quando são estabelecidas relaçôes estéticas.

A relação estética, um dos modos de relação do homem com a realidade, ${ }^{4}$ consiste em uma experiência pautada por uma sensibilidade que descola a ambos, sujeito e objeto, do imediato, da existência física e concreta. Ainda que subsista, essa existência aparece como mera condição para a afirmação do ser humano em sua plenitude.

Requer, portanto, a relação estética, que tanto o olhar ${ }^{5}$ do sujeito que admira quanto o objeto admirado se constituam enquanto tal, ou seja, enquanto estéticos. Quanto ao olhar estético, "é um olhar mais livre na sua apreensão significativa do mundo, pois busca outros ângulos de leitura, não para ver o objeto em sua pressuposta verdade, mas procurando, na relação estética com ele

3 A referência aqui são relações sociais pautadas por uma ética de bons encontros e a revolução das sensibilidades que significa uma existência estética, tal como discute Sawaia (1999).

4 Os modos de relação do ser humano com o mundo são "as relações práticoutilitárias com as coisas; relação teórica; relação estética, etc. Em cada uma dessas relações, modifica-se a atitude do sujeito para com o mundo, já que se modifica a necessidade que a determina e modifica-se, por sua vez, o objeto que a satisfaz" (Sánchez Vázquez, 1978, p.55).

5 Destaca-se o olhar como socialmente produzido, "porquanto sua apreensão não é de uma realidade dada, mas de uma realidade criada, ou seja, cultural. Não existe, portanto, 'o olhar', mas diferentes modos de ver segundo a referência do que é visto a sistemas específicos de atribuição de sentidos culturalmente produzidos” (Reis, Zanella, França e Ros, 2003a, p. 9). 
estabelecida, produzir novos sentidos para a configuração de realidades outras" (REIS, ZANELLA, FRANÇA e ROS, 2003a, p.10). O objeto estético, por sua vez, é aquele que transcende a função utilitária, sendo produzido para fins de deleite e prazer ainda que possa apresentar alguma função social. É, na verdade, o "testemunho objetivo da capacidade criadora do homem ou realidade humana objetivada" (SÁNCHEZ VÁZQUEZ, 1978, p. 76). Em suma, relação estética é relação sensível que, no prazer/desprazer, no deleite ou repulsa, forja a própria sensibilidade e se objetiva na atividade criadora.

Criar é, portanto, palavra da moda, como aponta Sawaia $(2000),{ }^{6}$ mas cuja presença e origem remonta a tempos difíceis de precisar. É atividade que caracteriza o ser humano e todas as suas produçóes, posto que "todos os objetos da vida diária, sem excluir os mais simples e habituais, vêm a ser algo assim como fantasia critalizada" (RIBEAU citado por VYGOTSKI, 1990, p. 10 - grifo do autor). Justifica-se, portanto, a necessidade de reflexóes constantes, de pesquisas sobre o tema e investimentos no que se refere à constituição de sujeitos criativos em qualquer âmbito de atuação profissional.

Com essa certeza é que constituímos um grupo integrado de pesquisa, inicialmente com duas pesquisadoras, ${ }^{7}$ ampliado a partir de meados de $2002^{8}$ e redimensionado em 2003. ' Nas investigações iniciais, centradas nas temáticas "constituição do sujeito" e "atividade criadora em contextos de ensinar e aprender", a coleta de informações e subsequente análise centraram-se em imagens, teste-

6 A autora faz referência ao conceito de "Tirania da Moda", utilizado por Jacques Bouveresse "para referir-se à pressão que faz com que os intelectuais franceses escrevam cada vez mais tendo em vista a recepção midiática" (Sawaia, 2000, p. 7).

7 A prof. Dra. Sílvia Zanatta Da Ros (MEN/CED/UFSC) e a prof. Dra. Andréa Vieira Zanella (PSI/CFH/UFSC).

$8 \mathrm{O}$ grupo, que trabalha com o projeto integrado de pesquisa "Constituição do Sujeito e Atividade Criadora: investigando professores das séries iniciais do ensino fundamental em contextos de formação continuada", é composto pelas seguintes pesquisadoras: Prof. Dra. Andréa Vieira Zanella (coordenadora do projeto - UFSC; bolsista em produtividade do CNPq); Prof. Dra. Cássia Ferri (UNIVALI); Prof. Dra. Kátia Maheirie (UFSC); Prof. Dra. Luciane Schlindwein (UNIVALI); Prof. Dra. Silvia Zanatta Da Ros (UFSC); Prof. Dra. Susana Inês Molon (FURG).

9 Em 2003, as perspectivas de investigação e organização do grupo começaram a se modificar a partir da colaboração do Prof. Dr.Angel Pino Sirgado (Univali/Unicamp), processo este que se encontra em andamento. 
Zanella, A. V.

"Atividade criadora, produção de conhecimentos e formação de pesquisadores: algumas reflexôes"

munhos e produções gráficas de acadêmicos de graduação em psicologia da UFSC.

Alguns resultados dessas investigaçôes podem balizar as reflexões sobre a formação de pesquisadores em contextos de pós-graduação, pois se necessário em todas as esferas da vida, a atividade criadora é também fundamental no universo da produção de conhecimentos.

$\mathrm{Na}$ condição de professora e orientadora de um programa de pós-graduação em psicologia, deparo-me constantemente com condições de trabalho e preocupações que não são prerrogativas do local específico em que me situo ${ }^{10}$ e interferem diretamente no grau de inovação possível objetivado nos percursos e resultados de pesquisa. Dentre essas condições destaco: prazos restritos para conclusão de cursos de pós-graduação, principalmente os mestrados (2 anos), considerando que grande parte dos alunos não conta com bolsa $\mathrm{e}$ trabalha durante todo o período da pesquisa; pressão dos órgãos de fomento sobre o programa e seus professores/orientadores no que se refere a resultados numéricos, dedicação cada vez maior aos programas, solicitações infindáveis de informações; exigência de publicações cada vez maior, com parcerias diversificadas (com colegas de linha, com alunos, com pesquisadores de outras instituições...), em alguns periódicos específicos e, se não bastasse, no exterior. Soma-se a isso o fato de que temos recebido candidatos aos programas de pós-graduação com formação geralmente precária no que diz respeito tanto a procedimentos de pesquisa quanto em termos epistemológicos, o que nos leva a uma sobrecarga ainda maior caso a exigência dos prazos seja levada a termo. Essa é a realidade que enfrentamos e ao mesmo tempo precisamos transformar. Haja criatividade, polivalência, flexibilidade!

Não me é possível apresentar propostas que resultem em melhoria dessas condições de trabalho, porém não consigo me isentar da responsabilidade em ao menos refletir sobre essa situação e buscar indicativos de mudança. Afinal, a resistência precisa de portos onde se assentar, e ainda que discorde de muitos dos critérios dos órgãos de fomento ou do modo como são implementados, creio

10 A esse respeito ver Bianchetti e Machado (org.), 2002. 
que referenciais outros precisam ser produzidos, em uma tarefa a que todos os envolvidos deveriam se engajar.

As reflexões que pretendo trazer resultam das investigações que vimos realizando. Estas resultaram, até o momento, em dois artigos publicados (ZANELLA, BALBINOT e PEREIRA, 2002; REIS, A. C., ZANELLA, A. V., FRANÇA, K. B., DA ROS, S. Z. 2003B), um artigo no prelo (REIS, A. C., ZANELLA, A. V., FRANÇA, K. B., DA ROS, S. Z., 2003A) e outro encaminhado para publicação (REIS, A. C., ZANELLA, A. V., FRANÇA, K. B., DA ROS, S. Z., 2003c).

Nessas investigações temos nos deparado com a vinculação inexorável entre atividade criadora e olhar estético, já explicitado neste texto. Depreende-se claramente que ambos se forjam mutuamente e são condição para a objetivação humana, ou seja, para a produção do novo decorrente da atividade criadora em qualquer esfera da vida, incluindo-se aí a produção de conhecimentos.

Historicamente separada da arte, a produção de conhecimentos que se pretendem transformadores da realidade social e comprometidos com sujeitos plenos não pode dela prescindir, pois a arte é “...o lugar privilegiado para a busca de utopias, uma vez que a ciência continua sua pesquisa sem fim perseguindo um conforto que, paradoxalmente, lança o homem na busca de instrumentos, transformando-o, no fim das contas, em um instrumento de consumir instrumentos" (VALADARES , 2003, p.202). Precisamos de utopias no campo da ciência também, pois estas, entendidas não como o impossível mas como devir, são o norte para a produção de conhecimentos que modificam ou mesmo revolucionam explicaçôes e modelos estabelecidos e socialmente aceitos.

Esses novos conhecimentos partem da leitura da realidade do material advindo da própria vida, como diz Vygotski (1998), e das explicações sobre esta já produzidas - e fornecem elementos que permitem transformá-la, pois toda realidade é histórica e, portanto, sujeita a mudanças. A sua produção, por sua vez, resulta não somente da disciplina teórica, do rigor metodológico e insistência de seus pesquisadores, mas também de uma certa dose de fantasia, emotividade e motivação, conforme De Masi (1999). 
Zanella, A. V.

"Atividade criadora, produção de conhecimentos e formação de pesquisadores: algumas reflexôes"

A estas condições acrescento outra, igualmente importante, aqui já referida: o olhar estético. Esse olhar amplia as possibilidades reflexivas e criativas do(a) pesquisador(a) na medida em que, por seu intermédio, descola-se da realidade e pode estranhá-la, condição esta para o reconhecimento da polissemia que a caracteriza e a torna multifacetada. Entende-se assim a necessidade imperiosa do olhar estético para pesquisadores que buscam, com sua atividade, produzir conhecimentos comprometidos com a realidade em sua complexidade e pretendem contribuir para que esta possa assim ser compreendida.

A constituição do olhar estético, por sua vez, decorre de um processo, de intervençóes deliberadas que objetivem romper com o episódico, com a explosão de imagens e mensagens desconexas que caracterizam a realidade atual e a destituem de sentidos voltados à crítica e sua transformação. Em uma das investigações realizadas, em que analisamos a intervenção de um educador voltada para a constituição do olhar estético, ${ }^{11}$ destacamos as seguintes atividades como fundamentais nesse processo: problematização de formas estereotipadas; convite à experimentação de outras formas de perceber e de se expressar criativamente; desestabilização da segurança da percepção do sujeito (no caso, uma aluna), a qual era limitada por um vocabulário pronto; desafio à descoberta de novos traços, novas formas, novos sentidos. ${ }^{12}$

E quanto ao novo, como promover a sua produção? Em outra pesquisa constatamos que "É o processo coletivo de produção de significaçóes ao que é considerado artístico que cria possibilidades de surgimento do novo. E o novo só é considerado como tal porque transforma, deforma e reforma o existente e, de certo modo, surpreende" (REIS, ZANELLA, FRANÇA e ROS, 2003b, p.16).

A produção do novo, no caso das pesquisas em contextos de pós-graduação, é mais uma demanda aos orientadores e acadêmicos que se soma as tantas já mencionadas (cumprimento de prazos, exigência de publicações, entre outras), e que se configura igualmente em dificuldade. Afinal, como se apropriar do existente - no caso, do

11 Ver Reis, Zanella, França e Ros (2003).

12 Traços e formas, na situação analisada, diziam respeito à atividade em questão, a saber, um desenho livre. 
que já se disse a respeito do que se pretende investigar, ainda que se demarque um referencial teórico norteador para essa busca - em tão pouco tempo? Quais os parâmetros para a delimitação do que é possível e pertinente ler/conhecer? Mais do que ler e conhecer, quais as condiçōes para se estabelecer relações dialógicas com esses múltiplos saberes de modo a estabelecer as aproximaçōes possíveis e distanciamentos necessários? Esse movimento de aproximações e distanciamentos, por sua vez, só se concretiza a partir de referenciais epistemológicos claros, mais uma conquista que com frequiência não acontece nos cursos de graduação.

Trata-se, portanto, de um grande empreendimento, em contextos de pós-graduação: a formação de pesquisadores criativos que contribuam para a produção de novos conhecimentos claramente marcados por um compromisso ético, político e estético. Compromisso esse que significa, em um primeiro momento, a constituição do olhar estético tanto de orientadores quanto de orientandos, o que implica por sua vez a constituição de relações estéticas e éticas.

Diante disso, pergunto: como lidar com angústias de orientadores e orientandos, com as dificuldades características do processo de formação de pesquisadores e ao mesmo tempo possibilitar condições de criação - produção criativa de conhecimentos? É possível investir em uma formação estética dos pós-graduandos? Como?

O percurso que tenho trilhado enquanto pesquisadora e professora/orientadora apontam algumas respostas: juntamente com o envolvimento com as respectivas pesquisas por parte dos pósgraduandos a partir do ingresso nos programas, destaca-se a necessidade de momentos para socialização e apropriação de conhecimentos específicos, o que leva a reafirmar a importância de que disciplinas específicas voltadas à reflexão teórica e epistemológica sejam oferecidas em contextos de PG; é fundamental também a reflexão sobre a relação epistemologia e pesquisa e a explicitação de polêmicas e relaçôes de poder que se apresentam no universo acadêmico; a produção de situações onde a leitura e problematização da realidade que a considere como complexa e multifacetada é igual- 
Zanella, A. V.

"Atividade criadora, produção de conhecimentos e formação de pesquisadores: algumas reflexôes"

mente importante; por fim, faz-se necessário a produção de espaços para a constituição de olhares estéticos que permitam a tessitura de relações marcadas pela possibilidade de reconhecimento tanto do espaço, do outro quanto de si mesmo em sua multiplicidade. $\mathrm{O}$ modo como essas diferentes necessidades podem se objetivar, por sua vez, é igualmente múltiplo, a depender da imaginação de seus autores/atores.

\section{REFERENNCIAS}

BIANCHETTI, L. \& MACHADO, A. M. N. (Orgs.) (2002). A Bússola do escrever: desafios e estratégias na orientação de teses e dissertaçôes. Florianópolis: Ed. da UFSC. São Paulo: Cortez, 2002.

GUATARRI, F. \& ROLNIK, S. (1986). Micropolitica: cartografias do desejo (2 ed.). Petrópolis: Vozes.

JUSTO, José Sterza (2001). Criatividade no mundo contemporâneo. Em: VASCONCELOS, Mário Sérgio (Org.). Criatividade: psicologia, educação e conhecimento do novo. São Paulo: Ed. Moderna, p.59-78.

REIS, A. C., ZANELLA, A. V., FRANÇA, K. B., DA ROS, S. Z. (2003a). Mediação pedagógica: reflexōes sobre o olhar estético em contexto de escolarização formal. Psicologia: Reflexão \& Crítica. Porto Alegre. No prelo.

REIS, A. C., ZANELlA, A. V., FRANÇA, K. B., DA ROS, S. Z. (2003b). Concepções de criatividade: movimentos em um contexto de escolarização formal. Psicologia em Estudo, Maringá/PR, v.8, $\mathrm{n}^{\circ} 1$ (pp.143-150), jan./jun.2003.

REIS, A. C., ZANELlA, A. V., FRANÇA, K. B., DA ROS, S. Z. (2002c). Doce, Pirâmide ou Flor? O processo de produção de sentidos em um contexto de ensinar e aprender. Artigo encaminhado para publicação na revista Interações. São Paulo/SP.

SANCHEZ VÁZQUEZ, A. (1978). As idéias estéticas de Marx. 2 ed. Rio de Janeiro: Paz e Terra. 
$=$ Psicologia \& Sociedade; 16 (1): 135-145; Número Especial 2004

SANCHEZ VÁZQUEZ, A. (1999). Convite à estética. Rio de Janeiro: Civilização Brasileira.

SAWAIA, B. B. (1999). Comunidade como ética e estética da existência. Uma reflexão mediada pelo conceito de identidade. Psykhe, vol.8, no1 (pp.19-25).

SAWAIA, B. B. (Org.) (2000). As artimanhas da exclusão: análise psicossocial e ética da desigualdade social. Petrópolis: Vozes.

VALADARES, J.C. (2003). Clínica psicanalítica e modernidade. Psicologia Clínica, v.15, nº1, Rio de Janeiro (pp. 201-206).

VYGOTSKI, L.S. (1990). La Imaginación y el Arte en la Infancia. Madrid: Akal.

VYGOTSKI, L.S. (1998) Psicologia da arte. Trad. Paulo Bezerra. São Paulo, Martins Fontes.

Andréa Vieira Zanella é professora do Progama de Pós-Graduação em Psicologia da Universidade Federal de Santa Catarina. $O$ endereço eletrônico da autora é: azanella@cfh.ufsc.br

Andréa Vieira Zanella

Atividade criadora, produção de conhecimentos e formação de pesquisadores: algumas reflexões

Recebido: 12/11/2003

$1^{\text {a }}$ revisão: $5 / 3 / 2004$

Aceite final: 10/4/2004 